\title{
Are there hopeless neighborhoods? An exploration of environmental associations between individual-level feelings of hopelessness and neighborhood characteristics
}

\author{
Christina Mair, Ph.D. ${ }^{1,2}$, George A. Kaplan ${ }^{3,4}$, and Susan A. Everson-Rose ${ }^{5}$ \\ Christina Mair: cmair@prev.org; George A. Kaplan: gkaplan@umich.edu; Susan A. Everson-Rose: saer@umn.edu \\ ${ }^{1}$ University of California Berkeley School of Public Health, Berkeley, CA \\ ${ }^{2}$ Prevention Research Center, Berkeley, CA \\ ${ }^{3}$ University of Michigan Department of Epidemiology, School of Public Health, Ann Arbor, MI \\ ${ }^{4}$ Center for Social Epidemiology and Population Health, University of Michigan, Ann Arbor, MI \\ ${ }^{5}$ Department of Medicine, University of Minnesota, Minneapolis, MN
}

\begin{abstract}
Feelings of hopelessness are prospectively associated with increased risk of death, progression of atherosclerosis and other health outcomes. Places as well as people may promote a sense of hopelessness. We used the Chicago Community Adult Health Study to investigate whether feelings of hopelessness cluster at the neighborhood level. Random-intercept logistic models were used to examine associations of hopelessness with neighborhood conditions (physical disorder and decay, perceived violence and disorder, social cohesion) and census-based measures of neighborhood socioeconomic conditions (poverty, unemployment, \% high school dropouts) from 1980-2000. Of the 3074 participants, 459 were categorized as experiencing hopelessness. Greater physical disorder and perceived disorder and a higher unemployment rate were associated with increased odds of hopelessness. Individuals' reports of hopelessness reflect physical, socioeconomic, and opportunity characteristics of their neighborhoods above and beyond their individual characteristics. Changing opportunity structures in a neighborhood may play a key role in reducing individuals' feelings of hopelessness.
\end{abstract}

\begin{abstract}
Keywords
hopelessness; neighborhood environments; neighborhood socioeconomic conditions; disorder; unemployment
\end{abstract}

\section{Introduction}

Hopelessness, defined as negative expectations about oneself and the future, is associated with many adverse health outcomes. Feelings of hopelessness often lead to high-risk

\footnotetext{
(C) 2012 Elsevier Ltd. All rights reserved.

Corresponding Author: Christina Mair, Prevention Research Center, 1995 University Ave, Suite 450, Berkeley, CA 94705 , cmair@prev.org, phone: (510)883-5762, fax: (510)644-0594.

Publisher's Disclaimer: This is a PDF file of an unedited manuscript that has been accepted for publication. As a service to our customers we are providing this early version of the manuscript. The manuscript will undergo copyediting, typesetting, and review of the resulting proof before it is published in its final citable form. Please note that during the production process errors may be discovered which could affect the content, and all legal disclaimers that apply to the journal pertain.
} 
behaviors such as substance use and aggressive behavior (Bolland, 2003). Hopelessness is prospectively associated with all-cause mortality, as well as cause-specific mortality from cardiovascular disease and violence and injury (Everson et al., 1996). Hopelessness is also related to progression of atherosclerosis, markers of endothelial dysfunction, incident myocardial infarction and incident cancer (Everson et al., 1996, Everson et al., 2000, Everson et al., 1997, Do et al., 2010). The number and strength of these associations speak to the importance of hopelessness in disease progression and mortality. Moreover, hopelessness appears to operate above and beyond depression and other mental health conditions (Greene, 1989). For example, hopelessness is not part of the diagnostic criteria for depression in the Diagnostic and Statistical Manual of Mental Disorders-IV (DSM-IV$T R$ ) (American Psychiatric Association, 2000). It also is clear that individuals may experience feelings of hopelessness without meeting criteria for depression (Whipple et al., 2009, Greene, 1989). The health effects of hopelessness may similarly be distinct.

Sociologists have investigated and described neighborhoods as hopeless, suggesting that hopelessness may characterize places as well as people. The opportunities literature posits that concentrated poverty, segregation and joblessness change individuals' attitudes and behaviors. Specifically, the concentration of economic and social problems in an area can lower hope about future opportunities for those who live in the area (Wilson, 1996).

Development of hopelessness amongst adolescents is associated with exposure to disruptive events such as violence and traumatic stress (Bolland et al., 2005, Stoddard et al., 2010), and exposure to these sorts of disruptive events is closely linked with living in certain types of neighborhood environments (Leventhal and Brooks-Gunn, 2000).

We are unaware of any studies that have looked at neighborhood-level variance in hopelessness or the characteristics of neighborhoods with high proportions of residents reporting feelings of hopelessness. In recent years research into associations between neighborhood environments and other mental health problems, particularly depression, has been growing (Diez Roux and Mair, 2010). These studies often find links between depression and neighborhood conditions such as neighborhood violence, social cohesion and physical disorder. It is unknown whether hopelessness is associated with similar neighborhood environments as depression or whether it has an independent, unique link to the places where people live. The purpose of this exploratory study was to examine the associations between feelings of hopelessness and neighborhood environments. Specifically, we investigated whether hopelessness clusters at the neighborhood level and the specific neighborhood characteristics and census-based measures of neighborhood socioeconomic conditions associated with individual-level hopelessness.

\section{Methods}

\section{Data sources and population}

The primary data source for this analysis is the Chicago Community Adult Health Study (CCAHS) (Morenoff et al., 2007). This stratified, multistage probability sample was collected in 343 neighborhood clusters in the city of Chicago, IL from May 2001 to March 2003. Clusters typically consist of two census tracts, and have meaningful physical and social borders. Cluster definitions were initially developed for the Project on Human Development in Chicago Neighborhoods (PHDCN) (Sampson et al., 1997). Subjects were oversampled from 80 focal neighborhood clusters, chosen for their heterogeneous socioeconomic and racial/ethnic composition. One adult aged 18 or over was interviewed from each sampled home. The final response rate was $72 \%$, high for a contemporary random population survey. The sample had an average of 9 subjects per neighborhood cluster (range: 1-21). This analysis used 3074 of the 3105 total study participants; 31 subjects missing information on the hopelessness measure were excluded from analyses. There were 
a few subjects missing individual-level covariate information (four missing education, three missing marital status, nine missing race/ethnicity). Case-by-case imputations were done for each missing value for these variables in order to maintain the sample size.

Sample weights were constructed and used in all data analyses to take into account the sampling approach, the differential participation rates by gender, income and race/ethnicity in the CCAHS, and to make the sample representative of Chicago. The final weight was a multiplicative combination of three weights: one adjusts for oversampling of individuals in focal neighborhood clusters, one adjusts for whether a participant was selected for intensive non-response follow-up at the end of the survey, and one post-stratification weight (to make the age, sex, and racial/ethnic composition of the sample match that of the city of Chicago circa 2003). The weight was centered to have a mean of 1.0 (range: 0.2-5.4) (Morenoff et al., 2007).

In order to examine associations between hopelessness and socioeconomic and opportunity characteristics of neighborhood environments, the Census CD Neighborhood Change Database (NCDB) was used (Tatian, 2003). This database combines information from the 1970, 1980, 1990 and 2000 long form US Census, and normalizes the data from 1970, 1980 and 1990 to the census tract boundaries of the 2000 census. This data set allows for historical analysis of census-based characteristics, including both neighborhood change between census years and summaries of neighborhood conditions across decades.

\section{Data variables}

Hopelessness was measured using four questions. Two of the questions were derived from the 2-item Kuopio Ischemic Heart Disease (KIHD) Hopelessness Scale: (1) I feel it is impossible for me to reach the goals that I would like to strive for and (2) The future seems hopeless to me and I can't believe that things are changing for the better (Everson et al., 1996). The other two questions came from the 20-item Beck Hopelessness Scale: (3) I don't expect to get what I really want and (4) There's no use in really trying to get something I want because I probably won't get it (Beck et al., 1974). Respondents had four potential responses to each question: Agree strongly, agree somewhat, disagree somewhat and disagree strongly. Each of the four items was dichotomized (any "agree" vs. any "disagree"). The four dichotomized responses were then summed, giving each respondent a hopelessness score ranging from 0-4 (4 representing the highest level of hopelessness).

Categorization of hopelessness items is consistent with previously published literature (Do et al., 2010, Everson et al., 1996, Everson et al., 1997, Everson et al., 2000) and fits with the conceptualization of the responses to the hopelessness items. This scale was then further dichotomized into "high hopelessness" (scores of 3 or 4 ) and "low hopelessness" (scores of $0,1,2)$. We examined associations with the hopelessness measures separately and continuously, and found no key differences between these sets of analyses.

Neighborhood conditions were measured using the CCHAS survey, rater assessments of the physical environment, and the US Census. Four neighborhood characteristics were constructed from the main CCAHS survey. These measures included perceived violence, perceived disorder, social cohesion and reciprocal exchange. Perceived disorder measures the conditions of the streets and buildings as well as public drunkenness and presence of unsupervised children. Reciprocal exchange represents neighborhood social resources that residents can draw upon for instrumental and emotional support. Social cohesion captures residents' perceptions of neighborliness and level of trust in the neighborhood environment. Perceived violence measures the frequency of specific types of violent events in the neighborhood. Violence, disorder and social cohesion were each made up of five items scored from 1-4, while reciprocal exchange included four items scored from 1-4. Each measure has been used in previous studies (Mair et al., 2010, Morenoff, 2003, Sampson and 
Raudenbush, 1999). Scales were aggregated to the neighborhood cluster level using empirical Bayes estimation. This method both adjusts for missing items and improves neighborhood-level estimates by borrowing information across neighborhood clusters (Mujahid et al., 2007).

Two neighborhood-level measures, physical decay and physical disorder, were constructed using systematic social observation (SSO), a method for gathering outside rater assessments of the physical environment (Sampson et al., 2007). Raters filled out a form for every block (four streets, eight street sides) on which at least one study participant lived. The blockgroup-level scale reliabilities of the physical disorder (0.94) and physical decay (0.65) measures were quite high. The SSO data included 6631 observations at the street level, with an average of 19.4 observations per neighborhood cluster. Physical disorder is a nine-item scale that describes the extent of negative neighborhood contamination such as graffiti, litter, abandoned cars and broken glass (Sampson and Raudenbush, 1999). Physical decay is a five-item scale that captures the deterioration and abandonment of residential, commercial, and recreational buildings on a block face (Mair et al., 2010).

Previous and current economic and opportunity characteristics were measured using NCDB data gathered from the 1980, 1990 and 2000 US Census. Cumulative measures from 1980 through 2000 as well as 2000-only variables were constructed for each census-based measure at the neighborhood cluster level. Change in environment between the 1990 and 2000 Census was also examined, but the change measures did not appear to be associated with hopelessness. This may be due to the fact that there was very little change in Chicago between these two census dates. Census-derived measures included poverty rate, unemployment rate, proportion Hispanic, proportion non-Hispanic black, proportion nonHispanic white, proportion foreign-born and proportion high school dropouts. The summaries of past neighborhood conditions were created by transforming the 1980,1990 and 2000 US Census measures into z-scores (mean 0, standard deviation 1) and summing.

All neighborhood variables were transformed into z-scores (mean 0 , standard deviation 1) in order to compare the strengths of associations between variables and to aid in the interpretation of coefficients. As these analyses were exploratory in nature and we had no a priori knowledge of the form of the relationships between the neighborhood characteristics and hopelessness, all neighborhood measures were broken into quartiles by neighborhood cluster ranking to allow for an examination of the shape of the relationship. As there were 343 neighborhood clusters in the data set, each quartile included either 85 or 86 clusters. Positive neighborhood characteristics, social cohesion and reciprocal exchange, were reverse-coded so that a higher quartile indicates a worse neighborhood environment. A summary measure of current neighborhood conditions was created by summing the z-scores of all the variables that were independently found to be associated with hopelessness $(p<0.05)$. The final neighborhood summary measure included physical disorder, perceived disorder, poverty rate, unemployment rate and the percent of high school dropouts.

Additional covariates included individual-level age, race/ethnicity, marital status, income, highest level of education achieved, and gender. Age was broken into six categories for analyses (18-29 years old, 30-39, 40-49, 50-59, 60-60, 70+). Race/ethnicity categories included non-Hispanic white, non-Hispanic African American, Hispanic and non-Hispanic other (3.8\% of the study population). Marital status was categorized into five groups: married, separated, divorced, widowed, and never married. Household income was categorized into six groups (\$0-4999, \$5000-9999, \$10000-29999, \$30000-49999, $\$ 50000+$ and missing $(18.8 \%)$ ). Highest level of education received was categorized into four groups (0-11 years, 12 years, 13-15 years, 16+ years). 


\section{Data analysis}

In order to determine the area-level variance in hopelessness, a median odds ratio (MOR) was calculated. This measure transforms area level variance to the odds ratio scale, an easily interpretable measure. The MOR is calculated using a simple formula described by Merlo et al (Merlo et al., 2006). The MOR can be interpreted as the median increased risk for high hopelessness when moving from a lower to a higher risk neighborhood cluster, or as the median value of the odds ratio (OR) comparing the higher risk to the lower risk of any two randomly picked neighborhood clusters. We also calculated the intraclass correlation coefficient (ICC) for our models using the formula ICC $=V_{A} /\left(V_{A}+V_{I}\right)$, where $V_{A}$ represents area-level variance and $V_{I}$ has a constant value of $\Pi^{2} / 3$. Because individual- and area-level variances are not directly comparable in multilevel logistic regression, this formula depends only on $\mathrm{V}_{\mathrm{A}}$ and serves as a proxy of an ICC from a linear model (Merlo et al., 2006).

Weighted distributions of all individual-level covariates were calculated for the entire study population. The weighted percent of individuals reporting high hopelessness in each population subgroup was also determined. We fit two-level logistic models with a random intercept for each neighborhood to examine associations between neighborhood characteristics and hopelessness before and after adjusting for individual-level sociodemographic variables. All models used the weights described above. Neighborhood characteristics were used as quartiles, with the comparison group representing neighborhoods reporting the lowest (worst) levels of each characteristic. Our modeling strategy was to insert each neighborhood variable one-at-a-time into models adjusted for individual-level covariates. An additional model was run using the neighborhood summary score to determine if the clustering of multiple neighborhood conditions had a stronger association with hopelessness than the independent effects of each neighborhood characteristic by itself. Finally, as a sensitivity analysis, models were re-run adjusting for depressive symptoms, which were measured by the abbreviated 11-item (Kohout et al., 1993) Center for Epidemiologic Studies Depression Scale (CES-D) (Radloff, 1977). All descriptive analyses were done with STATA version 9, and all of the random effects models were run using HLM version 6.06.

\section{Results}

Table 1 shows both the weighted distribution of individual-level covariates in the study population and the frequency of individuals reporting high hopelessness by those characteristics. Overall, $13.7 \%$ of the study population reported high hopelessness. Certain subgroups reported higher than average rates, such as Hispanics (20.4\%), non-Hispanic blacks (15.9\%), women (14.9\%), and widowed (26.6\%) and separated (21.5\%) individuals (Table 1). There were also strong trends by income (persons with lower income reported higher hopelessness), education (persons with less education reported higher hopelessness) and age (older individuals reported higher hopelessness). Study participants reporting high hopelessness also reported higher levels of depressive symptoms (mean 2.2) than the overall study population (mean 1.8).

The MOR, which illustrates the clustering of hopelessness at the neighborhood level, was 1.30 after taking into account the distribution of individual-level covariates. One interpretation of this MOR is that there is a $30 \%$ median increased risk of high hopelessness amongst residents in the more risky of two randomly selected neighborhood clusters. The ICC in the same adjusted model was $2.3 \%$.

Table 2 shows the associations between neighborhood characteristics and hopelessness adjusted for individual-level covariates. Each neighborhood characteristic was examined in 
its own model. Compared to the lowest quartile, living in a neighborhood in the highest quartile of physical disorder was associated with a $1.65(95 \%$ CI 1.07, 2.56) times greater likelihood of reporting high hopelessness. Similarly, living in a neighborhood with greater perceived disorder was associated with higher likelihood of reporting hopelessness (OR for highest vs. lowest quartile 1.89 (95\% CI 1.19, 3.00)). Higher perceived violence and poorer social cohesion also were associated with high hopelessness, although these trends were non-significant.

Table 3 presents the associations between US Census-derived measures of previous and current neighborhood conditions and hopelessness. Living in a neighborhood with a higher poverty rate was associated with higher odds of reporting hopelessness but these differences were not statistically significant (OR comparing highest vs. lowest quartile for 2000 Census 1.54 (95\% CI 0.95, 2.50); OR for the past summary measure of poverty was 1.46 (95\% CI $0.92,2.33)$ ). The second, third and fourth quartiles of the unemployment rate and proportion of high school dropouts had an increased likelihood of reporting high hopelessness as compared with the lowest quartiles. The highest quartile of unemployment rate had a significantly greater risk of hopelessness than the lowest (OR 1.99 (95\% CI 1.15, 3.46)). Similar associations were seen for the summary measures of neighborhood conditions from 1980-2000 for poverty rate, unemployment rate and high school dropout rate. None of the racial/ethnic or foreign-born variables was associated with high hopelessness.

The neighborhood summary score included neighborhood poverty rate, unemployment rate, proportion high school dropouts, perceived disorder and physical disorder. These variables were all independently associated with hopelessness in the prior multilevel logistic regression models. We found a trend by quartile for the neighborhood summary score. Living in a neighborhood reporting the highest levels of these conditions was associated with $1.90(95 \%$ CI 1.20 3.02) increased odds of reporting high hopelessness. It appears that living in neighborhoods with multiple negative environmental characteristics places residents at risk for reporting high hopelessness, although the magnitude of this association is similar to those between hopelessness and each individual characteristic. Adjusting models for depressive symptoms, as measured by the CES-D score, had very little impact on estimates. For example, the difference in neighborhood summary score between the highest and lowest quartiles of hopelessness changed from 1.90 (95\% CI 1.20,3.02) to 1.74 (95\% CI 1.07, 2.82) after adjustment for CES-D score. The second and third quartiles changed from $1.25(95 \%$ CI $0.83,1.88)$ to $1.22(95 \%$ CI $0.79,1.87)$ and from 1.39 (95\% CI 0.92 , $2.10)$ to $1.36(95 \% \mathrm{CI} 0.88,2.12)$, respectively. The qualitative patterns were unchanged after adjustment for depressive symptoms.

\section{Discussion}

Our study results demonstrate that feelings of hopelessness cluster at the neighborhood cluster level in Chicago (MOR=1.30). Measures of socioeconomic and opportunity characteristics and the physical environment were associated with hopelessness, while social conditions such as reciprocal exchange and social cohesion were not. Previous poverty measures and current poverty rates both predicted hopelessness equally well, which may reflect the fact that few Chicago neighborhoods had drastic socioeconomic changes between 1980 and 2000 (Sampson, 2009). Individuals living in neighborhoods with multiple risk factors for hopelessness had significantly higher odds of feeling hopeless than their counterparts living in neighborhoods with fewer neighborhood risk factors.

There is a growing awareness of the presence of hopeless feelings in poor, urban areas (Wilson, 1996) as well as the links between hopelessness and risky behaviors (Bolland, 2003) and mortality and morbidity (Whipple et al., 2009, Everson et al., 1996). Adolescents 
exposed to disruptive events and with less connectedness report development of hopelessness (Bolland et al., 2005), and adults who experienced multiple adverse childhood events are at increased risk of hopelessness (Haatainen et al., 2003a). Individual reports of unemployment, reduced working ability and poor financial situations are all associated with feeling hopeless (Haatainen et al., 2003b, Haatainen et al., 2004). We are aware of no previous quantitative studies of the associations between neighborhood environments and hopelessness. This study takes the mostly individual-level work a step farther by testing whether hopelessness clusters at the neighborhood level, and further determining what specific neighborhood environmental features are associated with high levels of hopelessness. We found that neighborhood economic conditions, above and beyond individual experiences within the labor market, contribute to hopelessness. There was no evidence that positive neighborhood social conditions are associated with less hopelessness.

One issue to consider is whether hopelessness and depression are unique health outcomes or whether hopelessness merely represents a piece of depressive symptomology. There is evidence that hopelessness is not a subtype of depression, but has its own predictors and health consequences (Henkel et al., 2002). Hopelessness may reflect one element of cumulative depression, while the CES-D score is a short-term measure of depressive symptomology. The correlation between our measure of high hopelessness and the modified CES-D scale was 0.27 , quite low. This correlation is consistent with other studies that have examined hopelessness and depression (Whipple et al., 2009, Everson et al., 1996). Furthermore, the shortened 11-item version of the CES-D scale (Kohout et al., 1993) used in these analyses did not include the one item in the full 20 item CES-D scale that measures hope (Radloff, 1977), so we have little reason to believe the two conditions are conflated in the data. Adjusting for depressive symptoms did not turn any significant $(\mathrm{p}<0.05)$ findings into non-significant ones, although some of the associations were slightly reduced. For example, the odds of hopelessness between the highest and lowest quartiles of the neighborhood summary score were reduced by approximately $8.5 \%$ (from $1.90(1.20,3.02)$ to $1.74(1.07,2.82))$.

The associations between hopelessness and neighborhood environments were distinct from our previous analysis looking at neighborhood associations with depressive symptoms in the same study population (Mair et al., 2010). In the prior analysis we found that individuals living in neighborhoods with low levels of social support and high levels of neighborhood stressors such as violence reported higher levels of depressive symptoms. Objective physical disorder and socioeconomic conditions were less strongly related to depressive symptoms than to hopelessness. These findings point to the independent influences of neighborhood environments on hopelessness and depression. Feelings of hopelessness may be more directly related to the perception of opportunities for the future, which are likely closely tied to unemployment and poverty. On the other hand, stressful neighborhood environments make individuals feel more depressed but social connections and social support within a neighborhood appear to directly buffer those negative effects in some individuals. Social cohesion and support do not appear to have the same protective effect on hopelessness that they do on depressive symptoms.

Our results add to the growing body of literature surrounding neighborhood effects on morbidity and mortality, and suffer from many of the common limitations. The CCAHS is an observational, cross-sectional study, and may be biased by unmeasured confounding (Oakes, 2004). We were unable to account for whether hopeless individuals selected into specific types of neighborhoods, or if those with feelings of hopelessness are less mobile than those who experience fewer feelings of hopelessness. This is the first study to look at neighborhood conditions and hopelessness, and results indicate that this is an avenue worth additional exploration. 
We were able to use previous measures of neighborhood socioeconomic conditions, but only under the assumption that residents had lived in the same neighborhood for the past 20 years. Histories of current neighborhoods and histories of the neighborhoods individuals have lived in are two separate concepts. It would be interesting to see whether an individual's cumulative environment and personal economic/employment history have a stronger association with feelings of hopelessness than current economic and neighborhood characteristics. While we controlled for income, education, and marital status, it is still likely that there remain unmeasured elements of individual-level socioeconomic status. This may have led us to overestimate the neighborhood associations with hopelessness.

Hopelessness is not just a characteristic of individuals, and it appears that neighborhoods can be characterized as hopeless as well. Our data suggest that the economic and physical characteristics of one's neighborhood environment uniquely contribute to feelings of hopelessness. It is easy to imagine how being unemployed and noticing that there are few opportunities for employment surrounding you work in conjunction to make you feel hopeless. It is important to consider environmental predictors for those at highest risk of hopelessness as this may point the way to potential intervention points within neighborhoods to reduce hopelessness. Structural characteristics, such as job opportunities, are a key point of intervention. Changing structural, opportunity characteristics of neighborhood environments is a difficult yet necessary task. Hopelessness contributes to many individuallevel health problems; addressing elements of neighborhood environments linked to hopelessness allows us to address these problems from a perspective that involves changing opportunity structures in neighborhoods rather than focusing solely on individuals.

\section{Acknowledgments}

This research was supported by Grant HD047861 from the National Institute of Child Health and Human Development.

\section{REFERENCES}

AMERICAN PSYCHIATRIC ASSOCIATION. Diagnostic and Statistical Manual of Mental Disorders. Arlington, VA: American Psychiatric Association; 2000.

BECK AT, WEISSMAN A, LESTER D, TREXLER L. The measurement of pessimism: the hopelessness scale. J Consult Clin Psychol. 1974; 42:861-5. [PubMed: 4436473]

BOLLAND JM. Hopelessness and risk behaviour among adolescents living in high-poverty inner-city neighbourhoods. J Adolesc. 2003; 26:145-58. [PubMed: 12581723]

BOLLAND JM, LIAN BE, FORMICHELLA CM. The origins of hopelessness among inner-city African-American adolescents. Am J Community Psychol. 2005; 36:293-305. [PubMed: 16389501]

DIEZ ROUX AV, MAIR C. Neighborhoods and health. Ann N Y Acad Sci. 2010; 1186:125-45. [PubMed: 20201871]

DO DP, DOWD JB, RANJIT N, HOUSE JS, KAPLAN GA. Hopelessness, Depression, and Early Markers of Endothelial Dysfunction in U.S. Adults. Psychosom Med. 2010; 72:613-9. [PubMed: 20498292]

EVERSON SA, GOLDBERG DE, KAPLAN GA, COHEN RD, PUKKALA E, TUOMILEHTO J, SALONEN JT. Hopelessness and risk of mortality and incidence of myocardial infarction and cancer. Psychosom Med. 1996; 58:113-21. [PubMed: 8849626]

EVERSON SA, KAPLAN GA, GOLDBERG DE, SALONEN JT. Hypertension incidence is predicted by high levels of hopelessness in Finnish men. Hypertension. 2000; 35:561-7. [PubMed: 10679498]

EVERSON SA, KAPLAN GA, GOLDBERG DE, SALONEN R, SALONEN JT. Hopelessness and 4year progression of carotid atherosclerosis. The Kuopio Ischemic Heart Disease Risk Factor Study. Arterioscler Thromb Vasc Biol. 1997; 17:1490-5. [PubMed: 9301625]

GREENE SM. The relationship between depression and hopelessness. Implications for current theories of depression. Br J Psychiatry. 1989; 154:650-9. [PubMed: 2597858] 
HAATAINEN K, TANSKANEN A, KYLMA J, HONKALAMPI K, KOIVUMAA-HONKANEN H, HINTIKKA J, VIINAMAKI H. Factors associated with hopelessness: a population study. Int J Soc Psychiatry. 2004; 50:142-52. [PubMed: 15293431]

HAATAINEN KM, TANSKANEN A, KYLMA J, HONKALAMPI K, KOIVUMAA-HONKANEN H, HINTIKKA J, ANTIKAINEN R, VIINAMAKI H. Gender differences in the association of adult hopelessness with adverse childhood experiences. Soc Psychiatry Psychiatr Epidemiol. 2003a; 38:12-7. [PubMed: 12563554]

HAATAINEN KM, TANSKANEN A, KYLMA J, HONKALAMPI K, KOIVUMAA-HONKANEN H, HINTIKKA J, ANTIKAINEN R, VIINAMAKI H. Stable hopelessness and its predictors in a general population: a 2-year follow-up study. Suicide Life Threat Behav. 2003b; 33:373-80. [PubMed: 14695052]

HENKEL V, BUSSFELD P, MOLLER HJ, HEGERL U. Cognitive-behavioural theories of helplessness/hopelessness: valid models of depression? Eur Arch Psychiatry Clin Neurosci. 2002; 252:240-9. [PubMed: 12451467]

KOHOUT FJ, BERKMAN LF, EVANS DA, CORNONI-HUNTLEY J. Two shorter forms of the CES-D (Center for Epidemiological Studies Depression) depression symptoms index. J Aging Health. 1993; 5:179-93. [PubMed: 10125443]

LEVENTHAL T, BROOKS-GUNN J. The neighborhoods they live in: the effects of neighborhood residence on child and adolescent outcomes. Psychol Bull. 2000; 126:309-37. [PubMed: 10748645]

MAIR C, DIEZ ROUX AV, MORENOFF JD. Neighborhood stressors and social support as predictors of depressive symptoms in the Chicago Community Adult Health Study. Health Place. 2010; 16:811-9. [PubMed: 20434941]

MERLO J, CHAIX B, OHLSSON H, BECKMAN A, JOHNELL K, HJERPE P, RASTAM L, LARSEN K. A brief conceptual tutorial of multilevel analysis in social epidemiology: using measures of clustering in multilevel logistic regression to investigate contextual phenomena. $\mathrm{J}$ Epidemiol Community Health. 2006; 60:290-7. [PubMed: 16537344]

MORENOFF JD. Neighborhood mechanisms and the spatial dynamics of birth weight. Ajs. 2003; 108:976-1017. [PubMed: 14560732]

MORENOFF JD, HOUSE JS, HANSEN BB, WILLIAMS DR, KAPLAN GA, HUNTE HE. Understanding social disparities in hypertension prevalence, awareness, treatment, and control: the role of neighborhood context. Soc Sci Med. 2007; 65:1853-66. [PubMed: 17640788]

MUJAHID MS, DIEZ ROUX AV, MORENOFF JD, RAGHUNATHAN T. Assessing the measurement properties of neighborhood scales: from psychometrics to ecometrics. Am J Epidemiol. 2007; 165:858-67. [PubMed: 17329713]

OAKES JM. The (mis)estimation of neighborhood effects: causal inference for a practicable social epidemiology. Soc Sci Med. 2004; 58:1929-52. [PubMed: 15020009]

RADLOFF L. The CES-D scale: a self-report depression scale for research in the general population. Applied Psychological Measurement. 1977; 1:385-401.

SAMPSON RJ. Racial Stratification and the Durable Tangle of Neighborhood Inequality. The ANNALS of the American Academy of Political and Social Science. 2009; 621:260-280.

SAMPSON, RJ.; MORENOFF, J.; RAUDENBUSH, SW.; SWAROOP, S. Ecometrics: The Use of Surveys and Observational Methods to Study Social Settings. In: WIKSTROM, PO., editor. Social Contexts of Pathways in Crime: Methods and Analytic Techniques. Cambridge, UK: Cambridge University Press; 2007.

SAMPSON RJ, RAUDENBUSH SW. Systematic Social Observation of Public Spaces: A New Look at Disorder in Urban Neighborhoods. American Journal of Sociology. 1999; 105:603-51.

SAMPSON RJ, RAUDENBUSH SW, EARLS F. Neighborhoods and violent crime: a multilevel study of collective efficacy. Science. 1997; 277:918-24. [PubMed: 9252316]

STODDARD SA, HENLY SJ, SIEVING RE, BOLLAND J. Social Connections, Trajectories of Hopelessness, and Serious Violence in Impoverished Urban Youth. J Youth Adolesc. 2010

TATIAN, PA. Neighborhood Change Database (NCDB): 1970-2000 tract data. Data users' guide, long form release [Online]. Washington, DC: Urban Institute; 2003. Available: http:// www.geolytics.com/pdf/NCDB-LF-Data-Users-Guide.pdf 
WHIPPLE MO, LEWIS TT, SUTTON-TYRRELL K, MATTHEWS KA, BARINAS-MITCHELL E, POWELL LH, EVERSON-ROSE SA. Hopelessness, depressive symptoms, and carotid atherosclerosis in women: the Study of Women's Health Across the Nation (SWAN) heart study. Stroke. 2009; 40:3166-72. [PubMed: 19713542]

WILSON, WJ. When Work Disappears: The World of the New Urban Poor. New York: Knopf; 1996. 


\section{Highlights}

- High hopelessness clusters at the neighborhood cluster level in Chicago.

- Socioeconomic and opportunity characteristics and the physical environment are associated with feelings of hopelessness.

- Social conditions (reciprocal exchange, social cohesion) are not associated with feelings of hopelessness. 
Table 1

Weighted Distribution of Individual-Level Covariates and \% Reporting High Hopelessness ( $\mathrm{n}=3074)$

\begin{tabular}{|c|c|c|c|}
\hline & & Prevalence (\%) & \% Reporting High Hopelessness \\
\hline & & & 13.7 \\
\hline \multirow[t]{6}{*}{ Age (years) } & $20-29$ & 27.7 & 8.6 \\
\hline & $30-39$ & 22.9 & 12.3 \\
\hline & $40-49$ & 18.8 & 11.7 \\
\hline & $50-59$ & 12.7 & 17.3 \\
\hline & $60-69$ & 8.7 & 21.6 \\
\hline & $70+$ & 9.2 & 23.8 \\
\hline \multirow[t]{4}{*}{ Race/Ethnicity } & Hispanic & 25.4 & 20.4 \\
\hline & Non-Hispanic White & 38.5 & 8.1 \\
\hline & Non-Hispanic Black & 32.3 & 15.9 \\
\hline & Other & 3.8 & 4.9 \\
\hline \multirow[t]{5}{*}{ Marital Status } & Married & 41.6 & 14.6 \\
\hline & Separated & 4.0 & 21.5 \\
\hline & Divorced & 10.9 & 15.2 \\
\hline & Widowed & 6.5 & 26.6 \\
\hline & Never Married & 37.0 & 9.1 \\
\hline \multirow[t]{6}{*}{ Annual Income } & $\$<5,000$ & 3.0 & 18.3 \\
\hline & $\$ 5,000-\$ 9,999$ & 7.0 & 23.7 \\
\hline & $\$ 10,000-\$ 29,999$ & 26.1 & 18.9 \\
\hline & $\$ 30,000-\$ 49,999$ & 18.6 & 9.0 \\
\hline & $\$ 50,000+$ & 26.6 & 7.5 \\
\hline & Missing & 18.7 & 15.2 \\
\hline \multirow[t]{4}{*}{ Education (years) } & $<12$ & 23.0 & 27.7 \\
\hline & 12 & 23.8 & 15.9 \\
\hline & $13-15$ & 25.1 & 10.0 \\
\hline & $16+$ & 28.1 & 3.6 \\
\hline \multirow[t]{2}{*}{ Gender } & Men & 47.6 & 12.3 \\
\hline & Women & 52.4 & 14.9 \\
\hline CES-D score & Mean/Mean for high hopelessness & 1.82 & 2.21 \\
\hline
\end{tabular}


Table 2

Adjusted Odds of Reporting High Hopelessness by Quartiles of Neighborhood-Level Characteristics $(\mathrm{n}=3074)^{* *}$

\begin{tabular}{|c|c|c|c|}
\hline Neighborhood Characteristic $^{\wedge}$ & Quartile & Quartile Range\% & OR $(95 \% \mathrm{CI})$ \\
\hline \multirow[t]{4}{*}{ Physical Disorder (SSO) } & $1^{\text {st }}$ & $-7.10,-2.91$ & Ref. \\
\hline & $2^{\text {nd }}$ & $-2.90,-1.77$ & $1.24(0.82,1.90)$ \\
\hline & $3^{\text {rd }}$ & $-1.76,-0.88$ & $1.30(0.89,1.90)$ \\
\hline & $4^{\text {th }}$ & $-0.87,1.75$ & $1.65(1.07,2.56)^{*}$ \\
\hline \multirow[t]{4}{*}{ Physical Decay (SSO) } & $1^{\text {st }}$ & $-4.65,-3.81$ & Ref. \\
\hline & $2^{\text {nd }}$ & $-3.80,-3.19$ & $0.87(0.60,1.27)$ \\
\hline & $3^{\text {rd }}$ & $-3.18,-2.54$ & $0.78(0.52,1.17)$ \\
\hline & $4^{\text {th }}$ & $-2.53,-0.96$ & $1.09(0.69,1.72)$ \\
\hline \multirow[t]{4}{*}{ Perceived Violence } & $1^{\text {st }}$ & $1.40-1.66$ & Ref. \\
\hline & $2^{\text {nd }}$ & $1.67-1.84$ & $0.69(0.46,1.03)$ \\
\hline & $3^{\text {rd }}$ & $1.85-2.03$ & $1.05(0.70,1.58)$ \\
\hline & $4^{\text {th }}$ & $2.04-2.67$ & $1.22(0.80,1.86)$ \\
\hline \multirow[t]{4}{*}{ Perceived Disorder } & $1^{\mathrm{st}}$ & $1.62,2.27$ & Ref. \\
\hline & $2^{\text {nd }}$ & $2.28,2.58$ & $1.62(1.09,2.42)^{*}$ \\
\hline & $3^{\text {rd }}$ & $2.59,2.91$ & $1.41(0.94,2.11)$ \\
\hline & $4^{\text {th }}$ & $2.92,3.41$ & $1.89(1.19,3.00)^{*}$ \\
\hline \multirow[t]{4}{*}{ Social Cohesion $^{11}$} & $1^{\text {st }}$ & $2.70,2.96$ & Ref. \\
\hline & $2^{\text {nd }}$ & $2.97,3.04$ & $0.92(0.63,1.35)$ \\
\hline & $3^{\text {rd }}$ & $3.05,3.12$ & $0.97(0.64,1.47)$ \\
\hline & $4^{\text {th }}$ & $3.13,3.45$ & $1.27(0.83,1.96)$ \\
\hline \multirow[t]{4}{*}{ Reciprocal Exchange $^{\wedge 1}$} & $1^{\mathrm{st}}$ & $2.55,2.78$ & Ref. \\
\hline & $2^{\text {nd }}$ & $2.79,2.86$ & $1.00(0.67,1.47)$ \\
\hline & $3^{\text {rd }}$ & $2.87,2.93$ & $1.10(0.73,1.66)$ \\
\hline & $4^{\text {th }}$ & $2.94,3.26$ & $1.15(0.79,1.66)$ \\
\hline \multicolumn{4}{|l|}{$\mathrm{p}<=0.05$} \\
\hline \multicolumn{4}{|c|}{ A All neighborhood variables are in z-score units (per 1 SD increase) } \\
\hline \multicolumn{4}{|c|}{ ** All models adjusted for individual level variables (marital status, age, education, income, race/ethnicity, gender) } \\
\hline
\end{tabular}

Health Place. Author manuscript; available in PMC 2013 March 01. 
Table 3

Adjusted Odds of Reporting High Hopelessness by Quartiles of Neighborhood Census Tract Characteristics $(\mathrm{n}=3074)^{* *}$

\begin{tabular}{|c|c|c|c|c|}
\hline Neighborhood Characteristic & Quartile & Quartile Range, $2000 \%$ & Sum $1980,1990,2000^{\wedge}$ & 2000 \\
\hline \multirow[t]{4}{*}{ Poverty Rate } & $1^{\text {st }}$ & $0.01,0.10$ & Ref. & Ref. \\
\hline & $2^{\text {nd }}$ & $0.11,0.18$ & $0.89(0.60,1.30)$ & $1.04(0.70,1.55)$ \\
\hline & $3^{\text {rd }}$ & $0.19,0.30$ & $0.83(0.54,1.26)$ & $0.93(0.60,1.45)$ \\
\hline & $4^{\text {th }}$ & $0.31,0.84$ & $1.46(0.92,2.33)$ & $1.54(0.95,2.50)$ \\
\hline \multirow[t]{4}{*}{ Unemployment Rate } & $1^{\mathrm{st}}$ & $0.01,0.05$ & Ref. & Ref. \\
\hline & $2^{\text {nd }}$ & $0.06,0.10$ & $1.34(0.87,2.07)$ & $1.60(1.06,2.41)^{*}$ \\
\hline & $3^{\text {rd }}$ & $0.11,0.17$ & $1.42(0.85,2.37)$ & $1.43(0.88,2.32)$ \\
\hline & $4^{\text {th }}$ & $0.18,0.49$ & $2.25(1.27,3.98)^{*}$ & $1.99(1.15,3.46)^{*}$ \\
\hline \multirow[t]{4}{*}{ Proportion Hispanic } & $1^{\mathrm{st}}$ & $0.00,0.01$ & Ref. & Ref. \\
\hline & $2^{\text {nd }}$ & $0.02,0.11$ & $0.75(0.45,1.25)$ & $0.86(0.52,1.41)$ \\
\hline & $3^{\text {rd }}$ & $0.12,0.42$ & $0.85(0.51,1.43)$ & $0.72(0.42,1.24)$ \\
\hline & $4^{\text {th }}$ & $0.43,0.97$ & $0.97(0.57,1.65)$ & $1.27(0.75,2.15)$ \\
\hline \multirow[t]{4}{*}{ Proportion NH Black } & $1^{\mathrm{st}}$ & $0.00,0.02$ & Ref. & Ref. \\
\hline & $2^{\text {nd }}$ & $0.03,0.21$ & $0.74(0.50,1.10)$ & $0.79(0.53,1.16)$ \\
\hline & $3^{\text {rd }}$ & $0.22,0.96$ & $0.76(0.47,1.22)$ & $0.81(0.49,1.34)$ \\
\hline & $4^{\text {th }}$ & $0.97,1.00$ & $0.92(0.50,1.69)$ & $1.05(0.57,1.96)$ \\
\hline \multirow[t]{4}{*}{ Proportion NH White } & $1^{\mathrm{st}}$ & $0.00,0.01$ & Ref. & Ref. \\
\hline & $2^{\text {nd }}$ & $0.02,0.14$ & $1.24(0.78,1.98)$ & $1.18(0.74,1.90)$ \\
\hline & $3^{\text {rd }}$ & $0.15,0.50$ & $0.75(0.45,1.27)$ & $0.94(0.55,1.59)$ \\
\hline & $4^{\text {th }}$ & $0.51,0.94$ & $0.93(0.51,1.71)$ & $0.76(0.40,1.41)$ \\
\hline \multirow[t]{4}{*}{ Proportion Foreign-Born } & $1^{\mathrm{st}}$ & $0.00,0.01$ & Ref. & Ref. \\
\hline & $2^{\text {nd }}$ & $0.02,0.15$ & $1.00(0.62,1.59)$ & $0.89(0.56,1.43)$ \\
\hline & $3^{\text {rd }}$ & $0.16,0.33$ & $0.83(0.49,1.41)$ & $1.14(0.67,1.97)$ \\
\hline & $4^{\text {th }}$ & $0.34,0.72$ & $1.06(0.62,1.81)$ & $1.09(0.64,1.85)$ \\
\hline \multirow[t]{4}{*}{ Proportion HS Dropouts } & $1^{\mathrm{st}}$ & $0,0.07$ & Ref. & Ref. \\
\hline & $2^{\text {nd }}$ & $0.08,0.13$ & $1.47(0.95,2.28)$ & $1.55(0.95,2.52)$ \\
\hline & $3^{\text {rd }}$ & $0.14,0.20$ & $1.38(0.90,2.11)$ & $1.38(0.87,2.19)$ \\
\hline & $4^{\text {th }}$ & $0.21,0.51$ & $1.50(0.93,2.43)$ & $1.52(0.93,2.49)$ \\
\hline \multirow[t]{4}{*}{ Neighborhood Summary Score ${ }^{\#}$} & $1^{\mathrm{st}}$ & $\mathrm{n} / \mathrm{a}$ & $\mathrm{n} / \mathrm{a}$ & Ref. \\
\hline & $2^{\text {nd }}$ & $\mathrm{n} / \mathrm{a}$ & $\mathrm{n} / \mathrm{a}$ & $1.25(0.83,1.88)$ \\
\hline & $3^{\text {rd }}$ & $\mathrm{n} / \mathrm{a}$ & $\mathrm{n} / \mathrm{a}$ & $1.39(0.92,2.10)$ \\
\hline & $4^{\text {th }}$ & $\mathrm{n} / \mathrm{a}$ & $\mathrm{n} / \mathrm{a}$ & $1.90(1.20,3.02)^{*}$ \\
\hline
\end{tabular}


${ }^{1}$ Sum of z-scores of 1980,1990, and 2000

p $<=0.05$

**

All models adjusted for individual level variables (marital status, age, education, income, race/ethnicity, gender)

\# Neighborhood summary score included poverty rate, unemployment rate, percent high school dropouts, perceived disorder and physical disorder

\%or Quartile Range, $\mathrm{n}=343$ neighborhood clusters 